\title{
Letter to the editor-a need to strengthen the adverse drug reaction reporting during COVID-19
}

\author{
Satvinder Singh Bakshi ${ }^{{ }^{*}}$ (D) and Sumita Bakshi
}

To the editor,

Since the outbreak of the coronavirus 2019 (COVID19) pandemic, the loss of life has been immense. Physicians have struggled to treat patients and have found them helpless in saving the lives of those affected. Such desperate times have created an environment where many known drugs have been tried for treating the infection. Many times, this has resulted in more harm than benefit; for example, one of the first therapies to be explored was chloroquine and hydroxychloroquine. This drug has long been used for malaria and inflammatory diseases. Many case studies and trials showed promise early on; however, there was minimal data on dosing regimen for effectiveness and safety. Eventually, in a randomized control trial, hydroxychloroquine treatment was shown to have no decrease in mortality and actually showed a higher incidence of mechanical ventilation and death [1].

Adverse drug reactions (ADRs) can be defined as "an appreciably harmful or unpleasant reaction resulting from an intervention related to the use of a medicinal product; adverse effects usually predict hazard from future administration and warrant prevention, or specific treatment, or alteration of the dosage regimen, or withdrawal of the product" [2]. They are one of the leading causes of hospital admissions and prolonged morbidity in patients in developed countries [2]. Many ADRs are underreported mainly because physicians and other support staff are unaware or do not consider it important to report [3].

Other drugs like antivirals/antiretrovirals like lopinavir have also been tried. Many times, the dosing of these

\footnotetext{
* Correspondence: saty.bakshi@gmail.com

'Department of ENT and Head \& Neck Surgery, AlIMS Mangalagiri, Post box 522503, Guntur, Andhra Pradesh, India

Full list of author information is available at the end of the article
}

drugs is above the standard dosing for the main disease they are meant for; this implies that the chance of adverse drug reactions is also high. Other drugs currently being used are ivermectin, doxycycline, azithromycin, and remdesivir [4]; in addition, multivitamins like vitamin $C$ and vitamin $D_{3}$ have also been advocated. The data on the adverse reaction of these drugs in COVID patients is limited; besides, since multiple medicines are being used, it is likely that the drug-drug interactions will also be higher. In their study, Crescioli $G$ et al. reported unexpected and uncommon psychiatric ADRs in hospitalized patients with COVID-19 infection; they also stressed on the burden of drug-drug interactions and the need to report them [5]. Some of the drug interactions reported by them include azithromycin with lopinavir, atorvastatin and warfarin and lopinavir with metformin, and levothyroxine [5].

At present, there is a paucity of any new drugs for tackling this infection; hence, we have to depend on these drugs for the time being. It is therefore imperative that physicians and other medical staff be sensitized to the need of reporting any ADRs in patients with COVID-19 infection. This will help build a good database and direct future research in the development of an efficacious and safe drug regimen for the management of COVID-19 infection. We also suggested that the patients themselves should be educated and sensitized to look for and report any adverse event they experience following the use of these drugs.

"Do no harm" or non-maleficence is the cornerstone of our medical practice, and adequate reporting of ADRs will go a long way in achieving the same.

\section{Abbreviations}

COVID-19: Coronavirus 2019; ADR: Adverse drug reaction

\section{Acknowledgements}

None 


\section{Authors' contributions}

SSB contributed to the conception, acquisition, and analysis of data and writing of the manuscript. SB contributed to the acquisition and interpretation of data and was a major contributor in writing the manuscript. Both the authors have read and approved the final draft of the manuscript and agree to be personally accountable for the author's own contributions.

\section{Funding}

No funding was obtained.

Availability of data and materials

Not applicable

\section{Declarations}

Ethics approval and consent to participate

Not applicable.

\section{Consent for publication}

Not applicable.

\section{Competing interests}

The authors declare that they have no competing interests.

\section{Author details}

'Department of ENT and Head \& Neck Surgery, AllMS Mangalagiri, Post box 522503, Guntur, Andhra Pradesh, India. ${ }^{2}$ Dr Smilez Dental Clinic, Pondicherry 605001, India.

Received: 28 June 2021 Accepted: 8 August 2021

Published online: 09 November 2021

\section{References}

1. RECOVERY Collaborative Group, Horby P, Mafham M, Linsell L, Bell JL, Staplin N et al (2020) Effect of hydroxychloroquine in hospitalized patients with COVID-19. N Engl J Med. 383(21):2030-2040. https://doi.org/10.1056/ NEJMoa2022926

2. Edwards IR, Aronson JK (2000) Adverse drug reactions: definitions, diagnosis, and management. Lancet. 356(9237):1255-1259. https://doi.org/10.1016/ S0140-6736(00)02799-9

3. Kharkar M, Bowalekar S (2012) Knowledge, attitude and perception/practices (KAP) of medical practitioners in India towards adverse drug reaction (ADR) reporting. Perspect Clin Res. 3(3):90-94. https://doi.org/10.4103/2229-3485.1 00651

4. Sanders JM, Monogue LM, Jodlowski TZ, Cutrell JB (2020) Pharmacologic treatments for coronavirus disease 2019 (COVID-19): a review. JAMA 323(18): 1824-1836. https://doi.org/10.1001/jama.2020.6019

5. Crescioli G, Brilli V, Lanzi C, Burgalassi A, leri A, Bonaiuti R, et al. Adverse drug reactions in SARS-CoV-2 hospitalised patients: a case-series with a focus on drug-drug interactions. Intern Emerg Med. 2021;16(3):697-710. https://doi.org/10.1007/s11739-020-02586-8.

\section{Publisher's Note}

Springer Nature remains neutral with regard to jurisdictional claims in published maps and institutional affiliations.

\section{Submit your manuscript to a SpringerOpen ${ }^{\circ}$ journal and benefit from:}

- Convenient online submission

- Rigorous peer review

- Open access: articles freely available online

High visibility within the field

- Retaining the copyright to your article 